\title{
Ultrastructural Localization of Dendritic Messenger RNA in Adult Rat Hippocampus
}

\author{
Maryann E. Martone, ${ }^{1}$ John A. Pollock, ${ }^{2}$ Ying Zhang Jones, ${ }^{1}$ and Mark H. Ellisman ${ }^{1}$ \\ ${ }^{1}$ National Center for Microscopy and Imaging Research at San Diego, Department of Neurosciences, University of \\ California San Diego, San Diego, California 92093-0608, and 2Department of Biological Sciences, Carnegie Mellon \\ University, Pittsburgh, Pennsylvania 15213
}

An ultrastructural examination of mRNA within adult rat CA1 hippocampal dendrites was conducted using two different methods. The messages for the $\alpha$ and $\beta$ forms of the calciumcalmodulin-dependent protein kinase II were localized in ultracryosections using silver-intensified gold detection of isoformspecific oligonucleotide probes. Labeling for both isoforms was observed within the cell bodies and proximal dendrites of pyramidal neurons, but only the $\alpha$ form was observed in more distal dendrites. Unfortunately, the morphological preservation of the tissue was not sufficient to determine the localization of labeling relative to subcellular features such as denritic spines. To address this issue, a preembedding peroxidase-based method was developed, resulting in better preservation of the neuropil. The total population of polyadenylated [poly $(A)]$ mRNA was localized in hippocampus using a biotinylated poly(dT) probe. Poly(A) mRNA was present in the nucleus and through- out the cell body of all hippocampal cells and within isolated dendrites and glial processes within the neuropil. Within pyramidal neurons, labeling was distributed in a longitudinal pattern in proximal apical dendrites. More distally, the amount of labeling diminished, and smaller foci of labeling were observed, particularly near the plasma membrane. Concentrated labeling was present at the base of dendritic spines and, less frequently, near synapses onto the dendritic shaft. These results suggest that dendritic mRNA is found in the vicinity of postsynaptic sites and provide additional evidence that local protein synthesis may play an important role in establishing and maintaining synaptic specializations.

Key words: in situ hybridization; electron microscopy; CAMKII; polyadenylated mRNA; dendritic spines; fluorescence in situ hybridization
The bulk of protein synthesis within neurons occurs in the perikaryon. However, increasing evidence suggests that dendrites also support the synthesis of some proteins in the mammalian nervous system. Dendritic protein synthesis was first proposed based on morphological evidence that dendrites, unlike most axons, contain polyribosomes (Steward and Levy, 1982) and on in situ hybridization studies localizing mRNAs for MAP2 and calcium-calmodulin-dependent protein kinase II (CAMKII) within dendrites (Garner et al., 1988; Burgin et al., 1990). Additional mRNAs have subsequently been found within dendritic processes (Furuichi et al., 1993; Landry et al., 1994; Miyashiro et al., 1994) and synaptosomes (Chicurel et al., 1993; Rao and Steward, 1993). Protein synthesis has been demonstrated in dendrites isolated from their cell bodies in culture (Torre and Steward, 1992), synaptosomal preparations (Rao and Steward, 1991; Weiler and Greenough, 1993), and dendritic fields of hippocampal slices (Phillips et al., 1987; Feig and Lipton, 1993).

Subcellular localization of mRNAs is an efficient mechanism for targeting proteins to their appropriate cellular locations and for allowing rapid and local control of protein synthesis within a particular cellular domain (Wilhelm and Vale, 1993). Dendrites are highly specialized subcellular compartments supporting the

Received July 19, 1996; revised Sept. 6, 1996; accepted Sept. 9, 1996.

This study was supported by National Institutes of Health Grants RR04050, NS14718, and NS26739 to M.H.E., and EY09093 to J.A.P. We thank Drs. Sui Huang, Paul Kelly, and Julie Goff for providing the oligonucleotide probes used in this study. Technical assistance was provided by Patricia Maurides.

Correspondence should be addressed to Maryann Martone, Department of Neurosciences, University of California San Diego, San Diego, CA 92093-0608.

Copyright (C) 1996 Society for Neuroscience 0270-6474/96/167437-10\$05.00/0 majority of synapses to a given neuron. Although the number of dendritic mRNAs conclusively identified is small, many of the molecules for which they encode are involved in signal transduction (Steward, 1995), indicating that these proteins could be synthesized near the sites where they are used. The hypothesis that dendritic mRNA functions in the development and maintenance of postsynaptic specializations is supported by findings that dendritic polyribosomes and some mRNAs are particularly numerous during periods of maximal synaptogenesis, e.g., during development and after deafferentation (Steward and Fass, 1983; Steward and Falk, 1986; Moriya and Tanaka, 1994) and that polyribosomes are preferentially localized near synaptic sites (Steward and Levy, 1982; Steward and Falk, 1986). The subsynaptic localization of polyribosomes has led to the additional hypothesis that protein synthesis may be regulated by synaptic activation allowing for local modification of activated synapses (Steward and Banker, 1992; Weiler et al., 1994; Steward, 1995).

Although the presence of mRNAs within synaptosomes suggests that a population of mRNAs exists near synapses, direct ultrastructural analyses of dendritic mRNA distribution have not been performed. Such analyses have been hampered by the lack of protocols combining sensitive detection methods with reasonable morphological preservation. We developed electron microscopic methods for the detection of mRNAs within the dendrites of hippocampal cells. Our initial efforts focused on the detection of specific messages for CAMKII isoforms. Using colloidal gold labeling of ultracryosections, we could detect these messages within hippocampal dendrites. A reasonably strong signal was obtained, but the degree of morphological preservation was not 
satisfactory for addressing the localization of mRNA relative to synaptic inputs and other subcellular structures. To address this issue, we employed a second method using a sensitive preembedding in situ hybridization technique to localize the total population of polyadenylated [poly(A)] mRNA. This work has appeared in abstract form (Martone et al., 1993, 1995).

\section{MATERIALS AND METHODS}

\section{Tissue}

Sprague Dawley rats of both sexes, aged 14-30 d, were anesthetized deeply with an anesthesia cocktail containing $50 \mathrm{mg} / \mathrm{kg}$ ketamine, $1 \mathrm{mg} / \mathrm{kg}$ rhompun, and $5 \mathrm{mg} / \mathrm{kg}$ acetopromazine in sterile saline and perfused transcardially with oxygenated rat Ringer's solution followed by a fixative solution consisting of $4 \%$ paraformaldehyde in $0.1 \mathrm{M} \mathrm{PBS}, \mathrm{pH} 7.2$, for light microscopic studies or $4 \%$ paraformaldehyde $/ 0.1 \%$ glutaraldehyde for electron microscopic studies. All solutions were prepared in diethylpyrocarbonate-treated water.

For the ultracryosectioning experiment, small blocks of tissue containing the hippocampus were cryoprotected for $1 \mathrm{hr}$ each in $0.5 \mathrm{M}$ sucrose in $0.1 \mathrm{M}$ PBS containing $2 \%$ paraformaldehyde, $1 \mathrm{M}$ sucrose in PBS containing $0.5 \%$ paraformaldehyde, and $2.3 \mathrm{M}$ sucrose in PBS. Tissue blocks were placed onto small aluminum screws and plunge-frozen in liquid propane using a Reichart-Jung KF-80. Frozen tissue blocks were stored in liquid nitrogen until cut.

For the preembedding protocol, blocks of tissue containing the hippocampus were cut on a a vibratome at a thickness of $50 \mu \mathrm{m}$ and processed free-floating.

\section{Probes}

A cDNA probe to CAMKII was generated from a $3.8 \mathrm{~kb}$ cloned restriction fragment corresponding to nucleotides 225-4010 of an $\alpha$-subunit cDNA provided to us by Dr. Paul Kelly (University of Texas Health Science Center). The $\alpha$-subunit mRNA of CAMKII is $\sim 5.3 \mathrm{~kb}$ with $\sim 1400$ bp of coding sequence. CAMKII probe was labeled by PCR amplification of the cloned insert through the use of the universal and reverse vector primers in the presence of either biotin-dUTP or digoxygenin-dUTP (80 ng template; 30\% labeled dUTP; 70\% dTTP; 6 min at $94^{\circ} \mathrm{C}$ (first cycle), $1 \mathrm{~min}$ at $94^{\circ} \mathrm{C}, 90 \mathrm{sec}$ at $60^{\circ} \mathrm{C}, 3 \mathrm{~min}$ at $72^{\circ} \mathrm{C}$, with an additional $6 \mathrm{sec}$ per cycle for 35 cycles). The PCR product was restriction digested with EcoRI, gel-purified, and recovered with glass milk (Geneclean; Bio 101, La Jolla, CA). A 600 bp fragment of the $3^{\prime}$-untranslated sequence was generally used as probe.

Isoform-specific $\alpha$ CAMKII and $\beta$ CAMKII oligonucleotide probes were generated as described by Burgin et al. (1990) with the exception that either biotin-dUTP or digoxygenin-dUTP was used instead of $\left[{ }^{35} \mathrm{~S}\right] \mathrm{dATP}$ as a label in the terminal transferase reaction.

The negative-control $\lambda$-DNA probe was generated by PCR, as described above, using the Bacteriophage Lambda DNA template and primers provided as control reagents in the Perkin-Elmer GeneAmp kit. This results in a labeled probe, $500 \mathrm{bp}$ long. The "no-probe" control consists of hybridization with hybridization buffer alone.

For the localization of poly(A)-containing messenger RNA, a 50mer poly(dT) oligonucleotide probe-tailed with biotin was kindly provided by Dr. Sui Huang (Cold Spring Harbor Laboratories, Cold Spring Harbor, NY). A similarly labeled poly(dA) probe was used a sense control. Probes were diluted in a hybridization cocktail consisting of $2 \times \mathrm{SSC}$ buffer, 1 $\mathrm{mg} / \mathrm{ml}$ tRNA, $10 \%$ dextran sulfate, and $25 \%$ formamide.

\section{In situ hybridization protocol}

Ultracryosections. The following is a modification of the procedure used by Pollock and co-workers $(1990,1991)$. Ultracryosections were cut at at thickness of $0.5-2.0 \mu \mathrm{m}$ on a Reichart Ultracut E with FC4E cryosectioning attachment. Cryosections were picked up on a bead of $2.3 \mathrm{M}$ sucrose and placed on formvar-coated, gold thin-bar EM grids, and washed in PBS. Pretreatment steps to render mRNA accessible to the probes included $0.1 \mathrm{~N} \mathrm{HCl}$ for $10 \mathrm{~min}$, followed by $2 \times \mathrm{SSC}$ at room temperature for $5 \mathrm{~min}$, then rapid heating to $70^{\circ} \mathrm{C}$, followed by fixation in buffered $4 \%$ paraformaldehyde $/ 0.1 \%$ glutaraldehyde. The tissue was then washed in PBS and subsequently exchanged with a $50 \%$ formamide -0.6 $\mathrm{M} \mathrm{NaCl}$ prehybridization buffer-lacking probe. The grids were then placed on drops of hybridization probe at $0.5-1.0 \mathrm{ng} / \mu \mathrm{l}$ in hybridization buffer. Hybridization was performed at $37^{\circ} \mathrm{C}$ overnight. Control sections in which the probe was omitted from the hybridization buffer or the sections treated with RNase before addition of probe were also included. The sections were then washed in formamide wash buffer at high stringency followed by washes in PBS.

Biotinylated RNA-DNA hybrids were detected with an anti-biotin primary antibody, followed by secondary antibody conjugated with $1 \mathrm{~nm}$ colloidal gold (Amersham, Arlington Heights, IL) and silver intensification (LI Silver, NanoProbe, Stonybrook, NY). Digoxygenin-labeled probes were detected using an unlabeled mouse anti-digoxygenin antibody (Boehringer Mannheim, Indianapolis, IN) followed by goat antimouse IgG conjugated to $1.4 \mathrm{~nm}$ colloidal gold (NanoProbe) and silver intensification. Sections were viewed at $400 \mathrm{keV}$ on a JEOL 4000EX intermediate-voltage electron microscope. Pilot experiments were carried out at $1 \mathrm{MeV}$ on a JEOL high-voltage electron microscope (University of Colorado, Boulder, CO).

Preembedding labeling of $\operatorname{poly}(A) m R N A$. Vibratome sections through the hippocampus were rinsed in PBS two times for $5 \mathrm{~min}$ followed by 5 min in PBS $/ 0.1 \%$ Triton $\mathrm{X}-100$, two times for $5 \mathrm{~min}$ in PBS, and two times for $10 \mathrm{~min}$ in $2 \times \mathrm{SSC}$. Sections were hybridized overnight in microcentrifuge tubes containing $4 \mathrm{ng} / \mu \mathrm{l}$ probe at $37^{\circ} \mathrm{C}$ in a water bath. After hybridization, sections were washed three times for $10 \mathrm{~min}$ each in $2 \times$ $\mathrm{SSC}$ at room temperature, one time for $30 \mathrm{~min}$ in $0.2 \times \mathrm{SSC}$ at $37^{\circ} \mathrm{C}$, and three times for $10 \mathrm{~min}$ in $2 \times \mathrm{SSC}$ at room temperature. Control conditions included omission of the probe from the hybridization buffer, substitution of a poly $(\mathrm{dA})$ sense probe in place of the antisense probe, or pretreatment of the sections with $100 \mathrm{ug} / \mathrm{ml}$ RNase for $2 \mathrm{hr}$ at $37^{\circ} \mathrm{C}$ before hybridization. Detection of the biotinylated probe for electron microscopic localization was accomplished using a multistep detection protocol adapted from McQuaid and Allan (1992). The following steps were used: (1) two $5 \mathrm{~min}$ washes in PBS; (2) $30 \mathrm{~min}$ in a mouse monoclonal anti-biotin antibody (Boehringer Mannheim) diluted $1: 30$ in $\mathrm{PBS}$ at $37^{\circ} \mathrm{C}$; (3) three $5 \mathrm{~min}$ washes in $1 \times \mathrm{PBS}$; (4) $10 \mathrm{~min}$ in biotinylated horse anti-mouse IgG (Vector Labs, Burlingame, CA), diluted 1:100 in PBS; (5) $60 \mathrm{~min}$ in streptavidin-horseradish peroxidase conjugate (Jackson Labs, West Grove, PA) diluted 1:100; (6) six 5 min washes in PBS; (7) 10 min

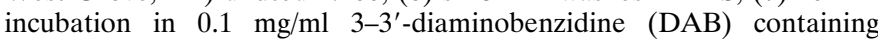
$0.008 \%$ hydrogen peroxide; (8) three 5 min washes in PBS; (9) $10 \mathrm{~min}$ in $2 \%$ glutaraldehyde; (10) three 5 min washes in PBS; (11) $30 \mathrm{~min}$ in $1 \%$ osmium tetroxide; (12) two 10 min washes in PBS; (13) dehydration in an ascending series of ethanol followed by $100 \%$ acetone; (14) flat embedding in Durcopan ACM resin (Electron Microscopy Sciences, Fort Washington, PA). Thin and semi-thin sections were cut on a Reichart Ultracut E ultramicrotome, collected on grids, and viewed on a JEOL 100CX or $2000 \mathrm{FX}$ electron microscope or a $4000 \mathrm{EX}$ intermediate high-voltage electron microscope. Most sections were viewed without counterstaining with heavy metals so as not to obscure the DAB reaction product. Some sections were counterstained with uranyl acetate and lead citrate before viewing under the electron microscope.

For light microscopic observation, streptavidin conjugated to fluorescein isothiocyanate was used in step 5 in place of the peroxidase conjugate. After rinsing in PBS, the sections were coverslipped in antifade medium without additional processing. Sections were viewed on a BioRad MRC 1024 laser-scanning confocal microscope.

\section{RESULTS}

\section{Localization of CAMKII mRNA in ultracryosections}

Both the 600 bp cDNA probe and the isoform-specific oligonucleotide probes resulted in labeling of pyramidal neurons in the CA1 region of hippocampus (Fig. 1). An example of a pyramidal cell body labeled with the cDNA probe is shown in Figure $1 A$. Membrane contrast was poor, although subcellular features such as the nucleus and the endoplasmic reticulum were distinguishable (Fig. $1 A, C$ ). Control experiments of "no-probe" treatment (Fig. $1 C$ ) or nonspecific $\lambda$ DNA (Fig. $1 B$ ) exhibited little background and were used to show that a signal-to-noise ratio of the density of silver-intensified gold particles was $\geq 10: 1$.

\section{Dendritic labeling}

Labeling for the $600 \mathrm{bp}$ cDNA and both oligonucleotide probes was observed within apical dendrites. However, distinct patterns of dendritic labeling were observed for the $\alpha$ and $\beta$ isoforms. Analysis of dendritic labeling patterns was performed in tissue 

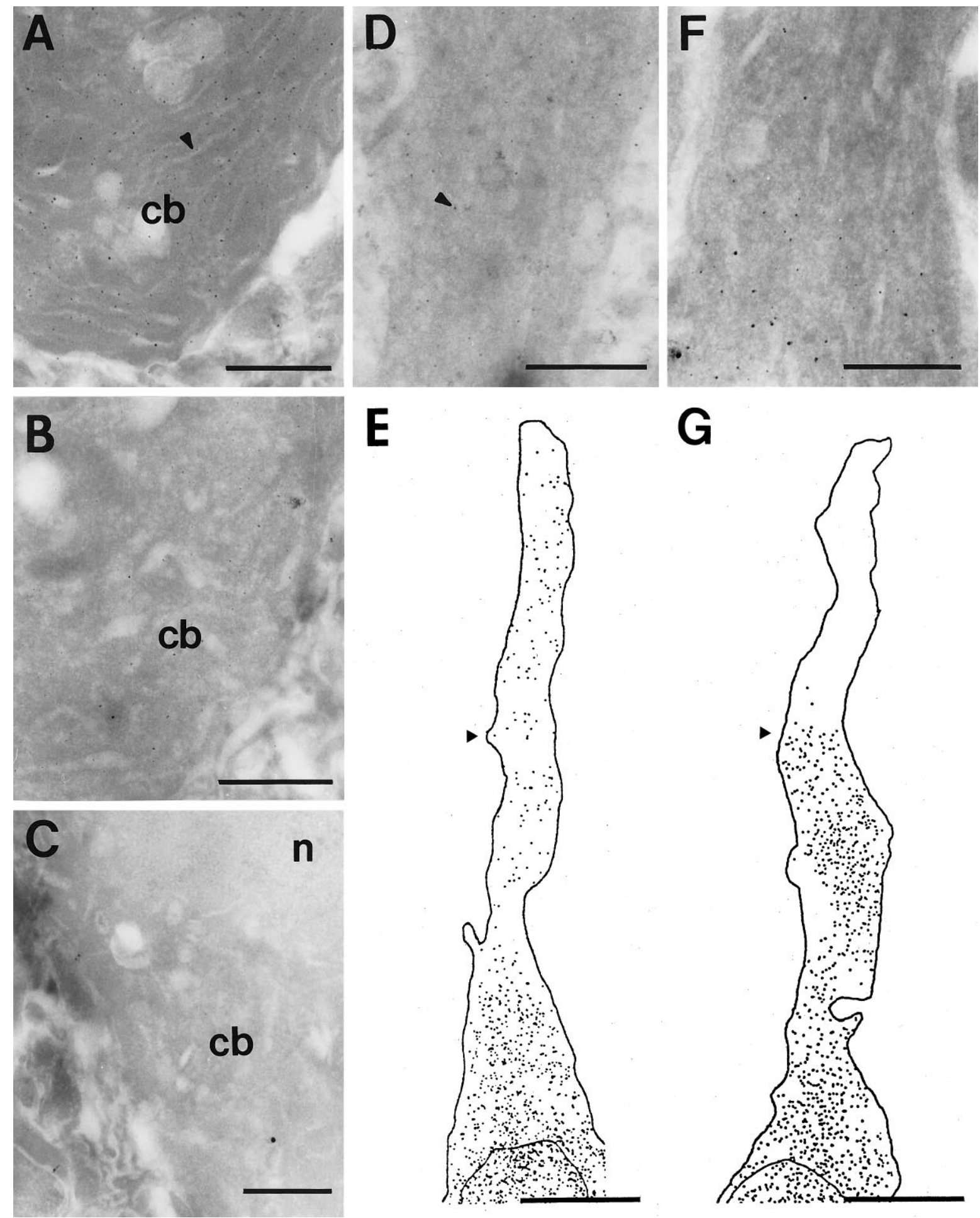

Figure 1. Localization of mRNA for CAMKII in 1- $\mu \mathrm{m}$-thick ultracryosections of CA1 pyramidal neurons hybridized with either the $600 \mathrm{bp}$ cDNA probe $(A)$ or the $\alpha$ - or $\beta$-specific probes $(D-G)$. $A$, Labeling with the $600 \mathrm{bp}$ CAMKII cDNA probe in a pyramidal cell body $(c b)$. Subcellular features such as the endoplasmic reticulum (arrowhead) were visible in such sections, although membrane contrast was poor. $B$, Control section hybridized with a 500 bp fragment of bacteriophage $\lambda$. A small amount of labeling is present within the cell body $(c b)$. $C$, Control section in which the probe was omitted from the hybridization solution. Little gold labeling was observed in the cell body $(c b)$ or nucleus $(n)$. $D, E$, Labeling for the $\alpha$ CAMKII mRNA in the cell body and apical dendrite of a pyramidal neuron. A tracing of the distribution of silver particles in a montage composed of four micrographs is shown in $E$. A micrograph through the portion of the dendrite indicated by the arrowhead is shown in $D$; the arrowhead points to a silver-intensified gold particle. Note that that labeling is fairly evenly distributed throughout the apical dendrite. $F$, $G$, The distribution of $\beta$ CAMKII mRNA in the apical dendrite of a pyramidal neuron. A tracing of the distribution of silver particles in a montage through the apical dendrite is shown in $G$. Note that the labeling abruptly stops at a distance of $\sim 15 \mu \mathrm{m}$ from the cell body. A micrograph through the region indicated by the arrowhead is shown in $F$. Scale bars: $A-D, F, 1 \mu \mathrm{m}$; $E, G, 10 \mu \mathrm{m}$. 
from two separate experiments based on montages through the cell body and apical dendrite. At least three dendrites were analyzed for each of the isoform-specific probes. Labeling for the $\alpha$ CAMKII isoform extended into the apical dendrites and could be followed for a distance of 30-40 $\mu \mathrm{m}$ from the cell body (Fig. $1 D, E)$. The intensity of signal gradually diminished with increasing distance from the cell body, and no labeling was observed within smaller-diameter isolated dendrites within the neuropil. This same pattern of labeling was observed for the $600 \mathrm{bp}$ probe. In contrast, when labeling for the $\beta$ CAMKII extended into proximal dendrites, it abruptly ceased at a distance of $\sim 15 \mu \mathrm{m}$ from the soma (Fig. $1 F, G)$. Counts of the silver-intensified gold particles indicated that a moderately strong signal terminated within a linear distance of $<1 \mu \mathrm{m}$. The manner in which the $\beta$ CAMKII mRNA signal terminates is reminiscent of the apparent restriction of mRNA transport into the axon initial segment (Kleiman et al., 1994).

\section{Localization of poly(A) containing mRNA}

Although the labeling of ultracryosections proved to be fairly sensitive, we were unable to examine the distribution of mRNA relative to synaptic sites or other subcellular structures, because the degree of ultrastructural preservation, particularly of the neuropil, was not adequate. We therefore turned to a preembedding method using peroxidase-based detection. Early attempts using the isoform-specific oligonucleotide probes were not successful. Therefore, to increase the likelihood of localizing mRNA within dendrites, we localized the total population of poly(A)containing mRNA using a poly(dT) oligonucleotide probe. By using a multistep detection method developed by McQuaid and Allan (1992), we were able to observe a strong dendritic signal in hippocampal pyramidal cells using both fluorescence and peroxidase-based detection.

\section{Light microscopy}

At the light microscopic level, poly(A) mRNA was found abundantly within the nucleus and cytoplasm of neurons and glial cells (Fig. $2 A, C$ ). In area CA1, fluorescent labeling extended for $>100$ $\mu \mathrm{m}$ within the apical dendrites of pyramidal cells. Within the nucleus, mRNA was distributed in a spotty pattern consisting of four or more focal concentrations of labeling, arranged in a ring around the nucleolus. The nucleolus and region adjacent to the nuclear membrane were unlabeled. Only light labeling of the cell bodies and nuclei was observed in the control conditions (Fig. $2 B, D)$.

\section{Electron microscopy}

The pattern of labeling observed in peroxidase-labeled sections at both the light and electron microscopic levels (Fig. $3 A, B$ ) was similar to that observed with fluorescence. Labeling was highly reproducible from experiment to experiment. Little labeling was observed in cell bodies and dendrites in the control conditions in either the light microscope (Fig. 3C,E) or electron microscope (Fig. $3 D, F)$. However, a small amount of punctate labeling was seen at the electron microscopic level within the neuropil in all of the control conditions. The number of labeled profiles was much lower in the control conditions than in the experimental conditions. To quantify the amount of nonspecific labeling, 10 fields of neuropil were photographed from the surface of the experimental and each of the control conditions: 5 at a magnification of $5000 \times$ and 5 at a magnification of $10,000 \times$. These photographs were analyzed blindly by one of the authors and the number of labeled
Table 1. Number of labeled profiles seen in randomly selected micrographs

Condition $\quad 0$ labeled profiles $1-2$ labeled profiles $\geq 3$ labeled profiles

\begin{tabular}{llll}
\hline Antisense & 0 & 0 & 10
\end{tabular}

$\begin{array}{llll}\text { Sense } & 3 & 3 & 4\end{array}$

$\begin{array}{llll}\text { RNAse } & 8 & 2 & 0\end{array}$

No probe $6 \quad 4 \quad 0$

Number of micrographs containing labeled profiles in each of the experimental conditions. Ten micrographs were obtained from the surface of tissue in the experimental and each of the control conditions. Micrographs were grouped according to the number of profiles observed $(0,1-2$, or $\geq 3)$. The number of micrographs falling into each category is reported for each condition.

profiles counted. The results are presented in Table 1. Among the control conditions, the largest number of labeled profiles were observed in the sense controls. The higher number of labeled profiles in this control condition could represent hybridization to poly $(\mathrm{T})$ stretches within mRNA molecules.

Electron microscopic observation focused on area CA1 of the hippocampus and were derived primarily from tissue from two animals that exhibited both good labeling and reasonable ultrastructural preservation. The heaviest labeling was observed within the nuclei and cell bodies of pyramidal cells and other cells in the molecular layer (Fig. 4). Within the cytoplasm, extensive punctate labeling was present within ribosome-containing regions of the cell soma (Fig. $4 A, B$ ). The Golgi apparatus and mitochondria were not labeled (Fig. 4A). Within the nucleus, poly(A)-containing mRNA was distributed in a prominent speckled pattern, as described previously by Spector and colleagues in non-neuronal cells (Spector, 1993; Huang et al., 1994). The nucleoli and heterochromatin were unlabeled (Fig. 4A,B). The pattern of nuclear staining appeared to differ between large and small cells. The speckles were much larger, rounder, and more darkly labeled in large cells compared with small cells, such as glia, in which staining was less intense and formed more of a filigree pattern (Fig. $4 B, E)$. In some cases, thin tracks of labeling were observed extending from the interior of the nucleus to the nuclear membrane, and accumulations of label were observed on the cytoplasmic side of the nuclear membrane (Fig. 4E, arrow). This pattern of labeling was reminiscent of recent results on poly(A) staining in the nucleus of cultured neurons, in which poly(A) mRNA was observed extending from the interior of the nucleus through the nuclear pores (Deerinck et al., 1994; Huang et al., 1994).

Labeling for poly(A) mRNA was observed in both apical and basilar dendrites but did not extend into axons beyond the beginning initial segment (Fig. 4C, arrow). Within apical dendrites, labeling was heaviest in the most proximal portions and decreased with distance from the soma (Fig. $3 B$ ). Label was distributed in a longitudinal pattern within proximal dendrites (Fig. $4 D$ ) but in a more punctate pattern in more distal regions. Even when sections were counterstained (e.g., Fig. 5C), it was difficult to identify the cytoskeletal or membrane components with which the labeling might be associated, because of both the weak fixation and tendency of DAB to stick nonspecifically to such structures.

Special attention was directed toward the relationship between the pattern of labeling and synaptic sites. The majority of dendritic spines observed emanating from labeled regions of dendrites had labeling associated with their base (Fig. $5 A, C$ ). In one instance, intense labeling was associated with a profile of endo- 

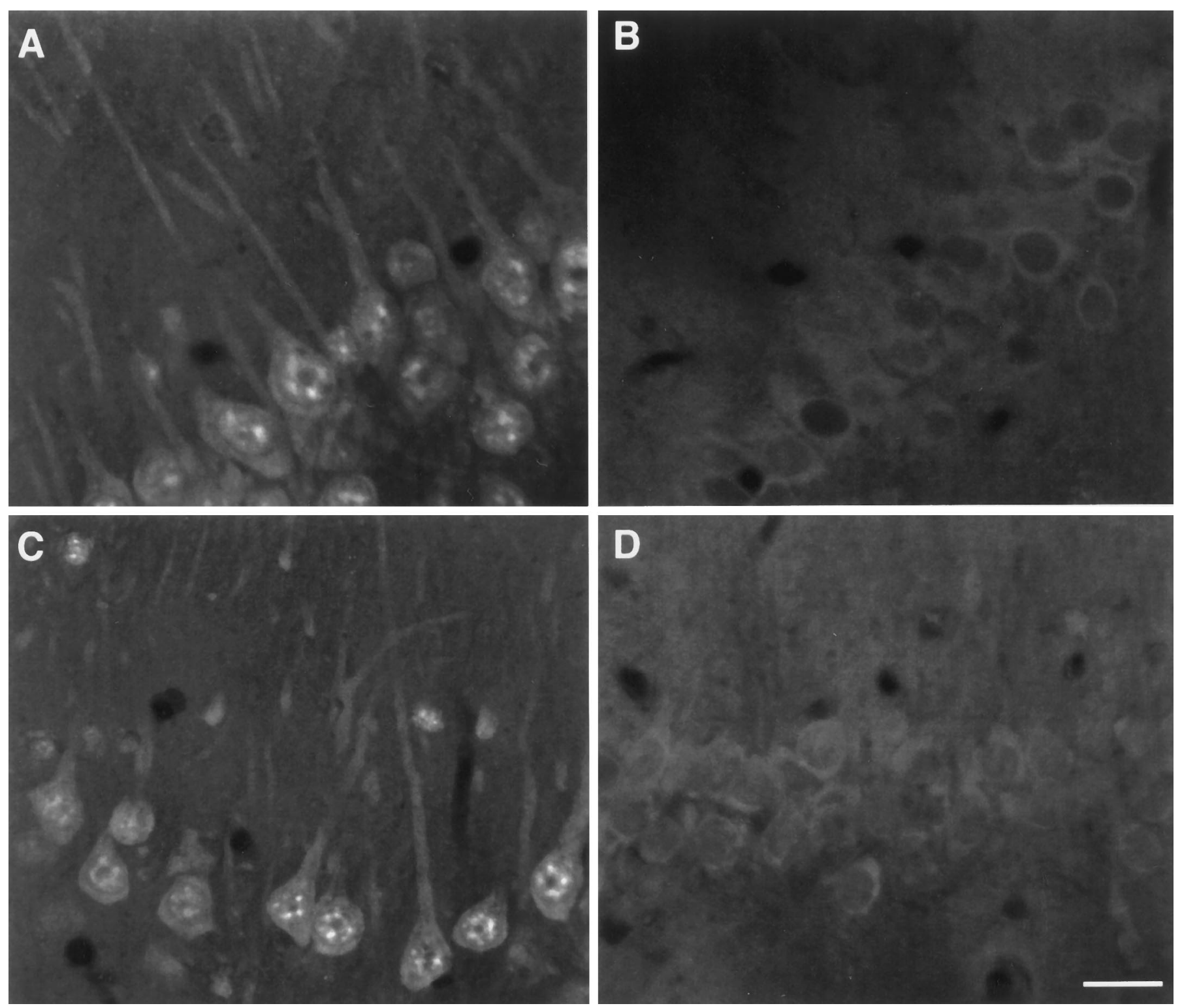

Figure 2. Fluorescence in situ hybridization of poly(A) mRNA in pyramidal neurons of area CA1. A, $C$, Sections labeled for poly(A) mRNA. Labeling could be followed within apical dendrites for a distance of $>100 \mu \mathrm{m}$. $B$, Control section hybridized with a poly(dA) sense probe. $D$, Control section in which no probe was included in the hybridization cocktail. Scale bar, $20 \mu \mathrm{m}$.

plasmic reticulum at the base of a large dendritic spine (Fig. $5 A$, arrows). A smaller number of spines had labeling extending into the spine head and shaft (Fig. 5B). Labeling was less reliably associated with synapses onto the dendritic shaft. In a small number of cases, concentrations of labeling were observed near the synaptic specialization (Fig. 4D, arrowhead). Most of the synapses onto the dendritic shaft had only light labeling within the vicinity of the postsynaptic specialization (Fig. $5 A, D$ ), even when followed through serial sections. No labeling was observed near a symmetrical synapse observed onto the axon initial segment (data not shown). Much of the subplasmalemmal labeling observed in dendrites was not associated with either dendritic spines or synaptic sites. However, subplasmalemmal labeling was often observed where the plasma membrane bulged out slightly from the dendrite (Fig. 5E, arrowheads). These mounds could represent sites where denritic spines emerge out of the plane of section, although an analysis of short series of serial sections (10-15 sections) could not always reliably identify a dendritic spine associated with these foci.

Within the neuropil, labeling was observed in isolated dendrites, glial processes, and many small unidentifiable profiles, none of which was clearly presynaptic. Labeled astrocytic processes were sometimes observed apposed to synaptic complexes (Fig. $5 F$ ). Several examples of labeled spines attached to unlabeled dendrites were also observed within the neuropil (data not shown). However, extensive evaluation of the control material revealed that lightly labeled spines attached to unlabeled dendrites were also present in all three control tissues examined. Although not frequently encountered, at least one labeled spine was observed in each of the control sections taken from two different animals. This type of nonspecific labeling persisted even when no peroxidase was applied to the tissue, suggesting that some peroxidase-like activity may be present within spine heads. 

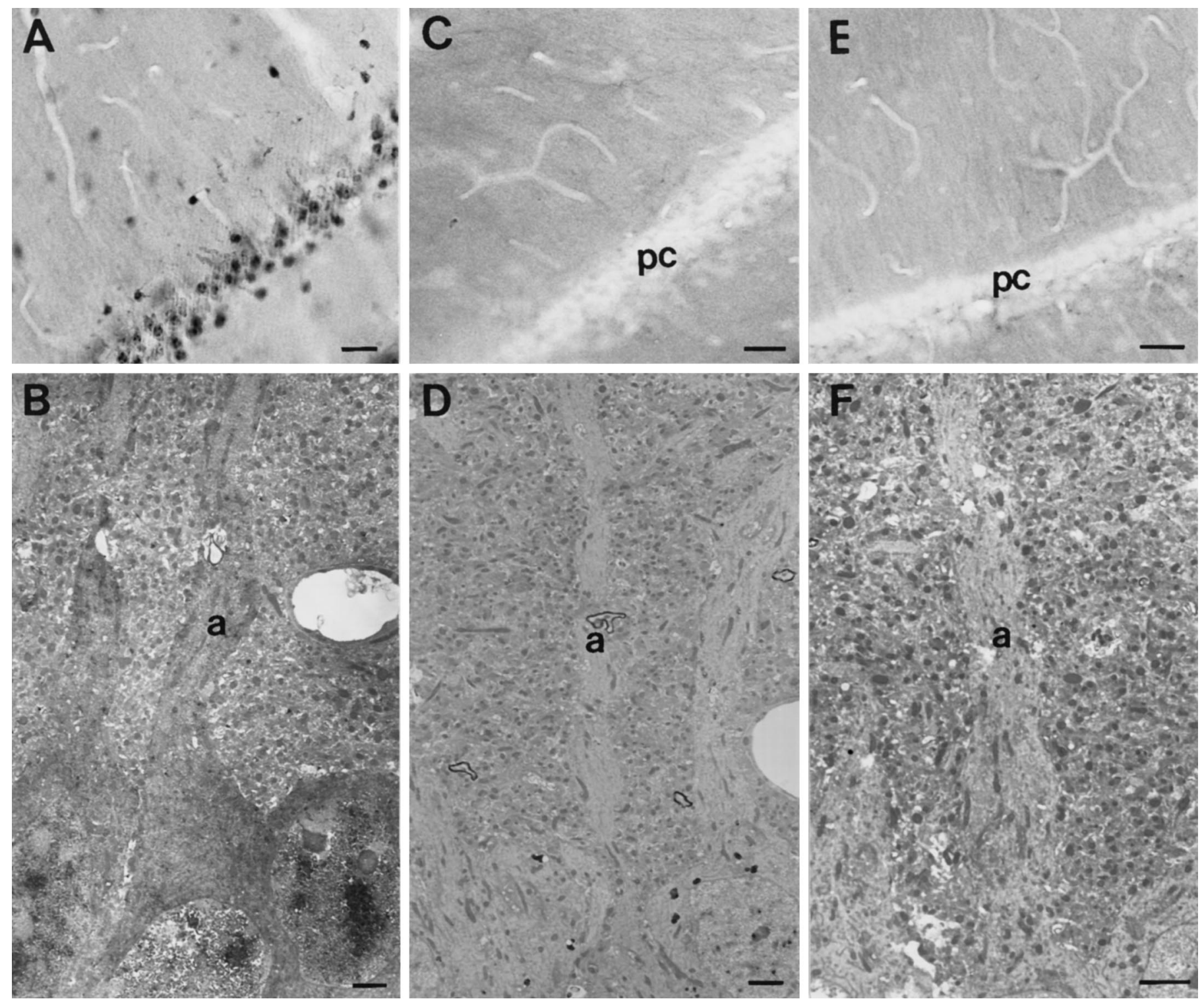

Figure 3. Peroxidase labeling for poly(A) mRNA labeling in area CA1 in experimental and control conditions at the light microscopic $(A, C, E)$ and electron microscopic $(B, D, F)$ levels. $A, B$, Pyramidal neurons labeled for poly(A) mRNA. At both the LM and EM levels, staining was observed within cell bodies, nuclei, and apical dendrites $(a)$. $C, D$, Pyramidal cell layer $(p c)$ hybridized with the sense probe. $E, F$, No probe control. In neither control condition was labeling observed within the pyramidal cell layer $(p c)$ or apical dendrites $(a)$. All electron micrographs were taken from the surface of the tissue. Scale bars: $A, C, E, 100 \mu \mathrm{m} ; B, D, F, 2 \mu \mathrm{m}$.

\section{DISCUSSION}

This study provides the first ultrastructural demonstration that mRNA is found close to the base of dendritic spines and near synaptic specializations. These results support the hypothesis that polyribosomes localized at these sites are engaged in protein synthesis. The significance of this arrangement will be considered below.

\section{Electron microscopic in situ hybridization detection}

The repeated demonstration of subcellular targeting of mRNA species has led to the need for high-resolution in situ hybridization techniques. We and others have found that the use of ultracryosections combined with colloidal gold detection provides a fairly sensitive method for localizing individual messages ultrastructurally (Pollock et al., 1990; Wenderoth and Eisenberg, 1991). This approach afforded acceptable ultrastructural preservation of cell bodies within the rat hippocampus, but the structure of the neuropil was severely compromised. The degree of preservation could be improved by using thicker specimens $(>1 \mu \mathrm{m})$, but the staining patterns were difficult to interpret in this material because of overlapping of structures in the neuropil. The preembedding approach used in the present study resulted in much better preservation of the neuropil. However, the sensitivity of this protocol is less than the cryosection method, and we have been unable to demonstrate the localization of individual messages. Efforts are underway to explore additional amplification schemes that may boost the signal, along with methods to improve the structure of ultracryosection-based methods.

\section{Transport of mRNA within dendrites}

The most striking finding with the probes to CAMKII isoforms was the abrupt cessation of labeling along the length of the apical 

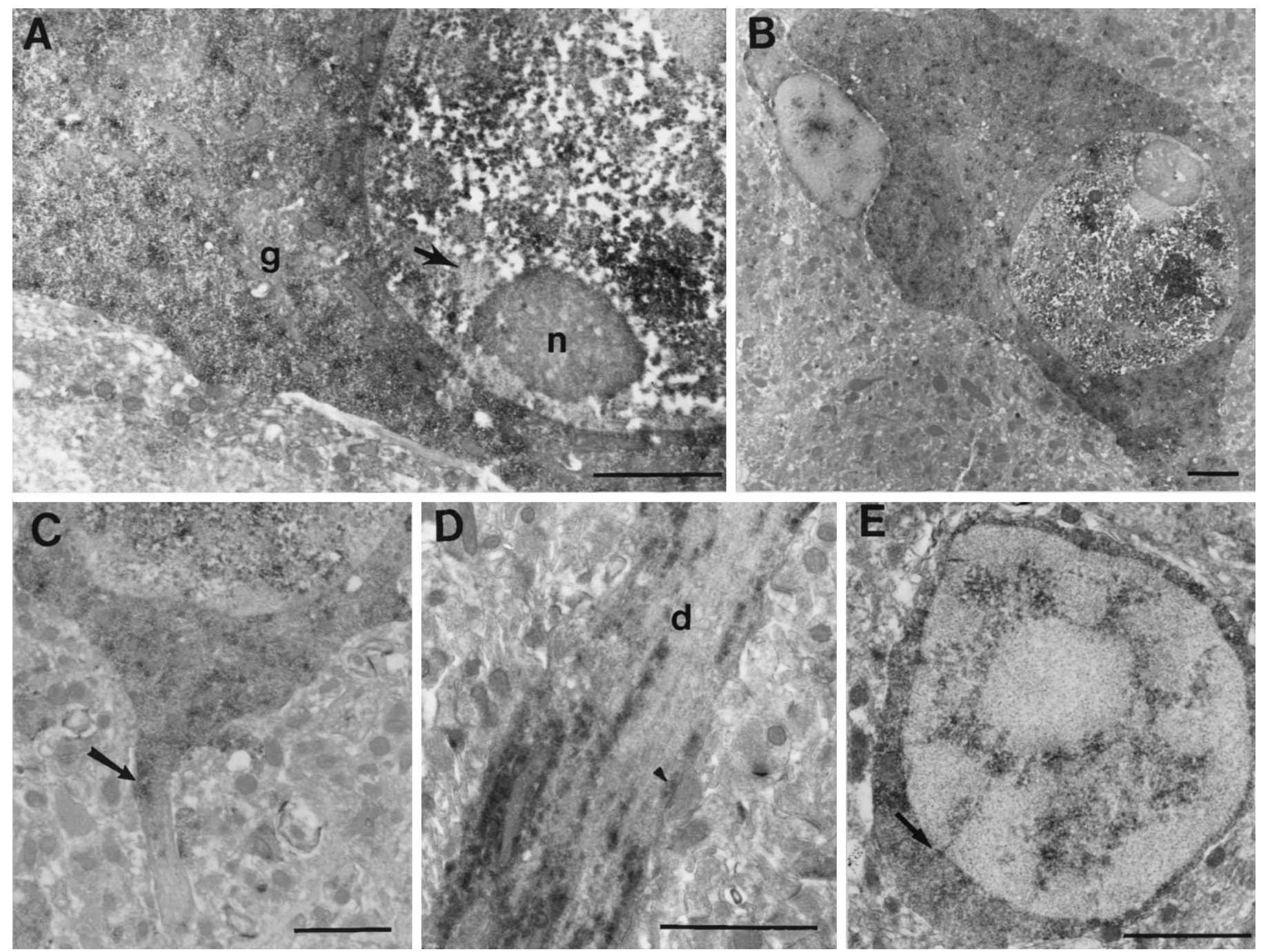

Figure 4. Ultrastructural localization of poly(A) mRNA in cell bodies and dendrites of rat hippocampal cells. $A$, Labeled pyramidal cell body. Both densely labeled foci and a more diffuse background staining were observed in the nucleus, although neither the nucleolus $(n)$ nor the heterochromatin (arrow) was labeled. Labeling was present in a finer punctate pattern in the cytoplasm that was not associated with the Golgi apparatus ( $g$ ) or mitochondria. $B$, Large neuron flanked on the left by a smaller satellite cell. The nuclear speckles were larger and more intensely labeled in the large neurons compared with smaller glial cells. $C$, Axon initial segment of a labeled pyramidal neuron (arrow). Labeling extended into the beginning portion but then terminated. $D$, Pyramidal cell dendrite $(d)$. Labeling was distributed in a roughly longitudinal pattern within heavily labeled dendrites. The arrowhead points to a concentration of labeling underneath a synaptic apposition onto the dendritic shaft. $E$, Small, likely glial, cell showing the distribution of poly(A) mRNA within the nucleus. In this cell, tracks of mRNA radiate from the interior of the nucleus to the nuclear membrane and perhaps into the cytoplasm (arrow). Scale bars, $1 \mu \mathrm{m}$.

dendrite. Analysis of well-preserved specimens suggests that the area of termination of the $\beta$ signal corresponds to a region of significant morphological change within the dendrite where the amount of Golgi apparatus and rough endoplasmic reticulum (RER) precipitously decreases (our unpublished observations). Thus, the signal for $\beta$ CAMKII coincided with regions of the proximal dendrite that were more similar in morphology to the cell soma than to more distal dendrites. This localization is consistent with that found by Burgin and co-workers (1990), who reported that $\beta$ CAMKII mRNA is restricted to cell bodies in the rat hippocampus. The rather abrupt cessation of signal along the apical dendrite suggests that beyond a certain point, mRNAs are either selectively transported into or stabilized within distal dendrites. Evidence for selective transport of mRNA into dendrites has been provided in vitro (Davis et al., 1987; Kleiman et al., 1994).
Labeling for poly(A) mRNA was distributed longitudinally within proximal dendrites. Association of this label with particular subcellular structures could not be made conclusively, but the labeling pattern was consistent with an association between mRNA and microtubules, which also run longitudinally within dendrites (Peters et al., 1991). Interactions between mRNA and microtubules have been noted in cultured neurons (Ainger et al., 1993; Bassell et al., 1994; Litman et al., 1994) and other cell systems in which the integrity of the microtubule cytoskeleton is necessary for the correct subcellular targeting of mRNA (Pokrywka and Stephenson, 1991). Messenger RNAs destined for subcellular targeting contain specific protein binding sites in their $3^{\prime}$-untranslated ends, permitting the interaction of the mRNA with the cell's cytoskeleton (MacDonald and Struhl, 1988; Mowry and Melton, 1992; Elisha et al., 1995). 

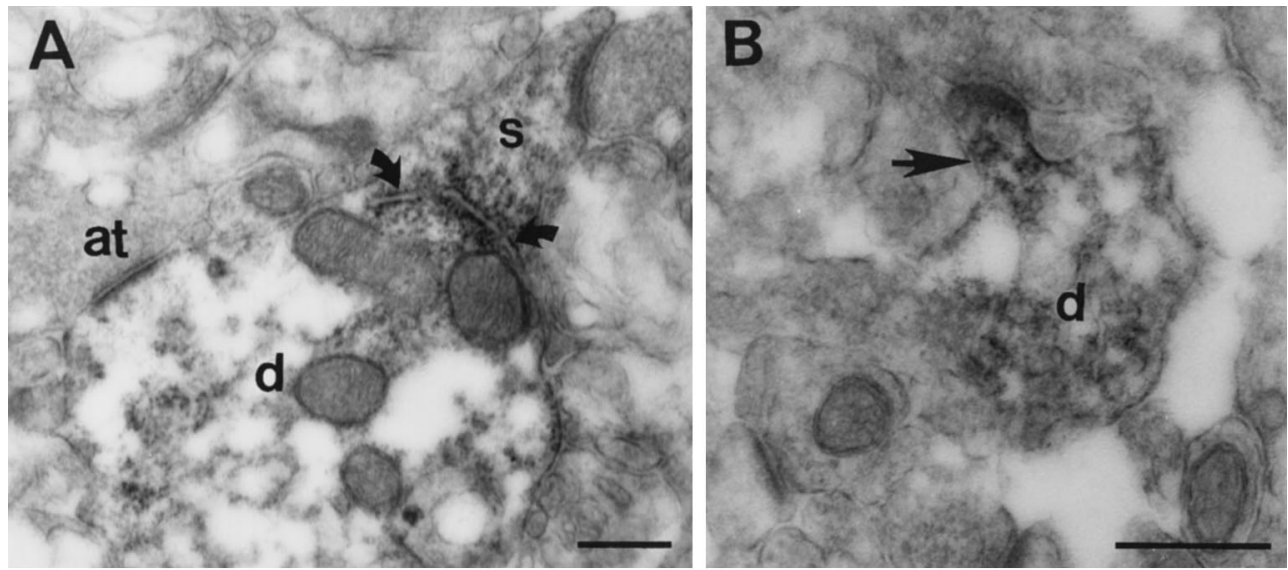

Figure 5. Ultrastructural localization of poly(A) mRNA in isolated dendrites and processes within the neuropil. $A$, Crosssection of a spiny dendrite $(d)$ with a large spine $(s)$ attached. Intense labeling is present associated with a membranous profile at the base of the spine (curved arrows). Little labeling is present near the axonal terminal (at) onto the dendritic shaft. $B$, Cross-section of a small spiny dendrite $(d)$ with a labeled spine (arrow) attached. $C$, Longitudinal labeled dendrite $(d)$ with a spine $(s)$ attached. Concentrated labeling and a profile of endoplasmic reticulum are present at the base of the spine (arrow). This tissue was counterstained with uranyl acetate and lead, which obscured the labeling to some extent. $D$, Cross section of a labeled dendrite $(d)$ with an axon terminal (at) forming a symmetrical synapse. The heaviest staining within the dendrite is not associated with the synaptic site. $E$, Longitudinal labeled dendrite $(d)$ with two spines (s) nearby but not attached. Labeling within the dendrite is associated with slight bulges in the plasma membrane (arrowheads), which may represent sites of attachment of dendritic spines that are out of the plane of section. The spine to the lower right shows labeling (arrow) in what could be a spine neck attached to a nearby dendrite. $F$, Labeling of a glial process $(g)$ apposed to a synaptic complex in the neuropil. Scale bars, $500 \mathrm{~nm}$.
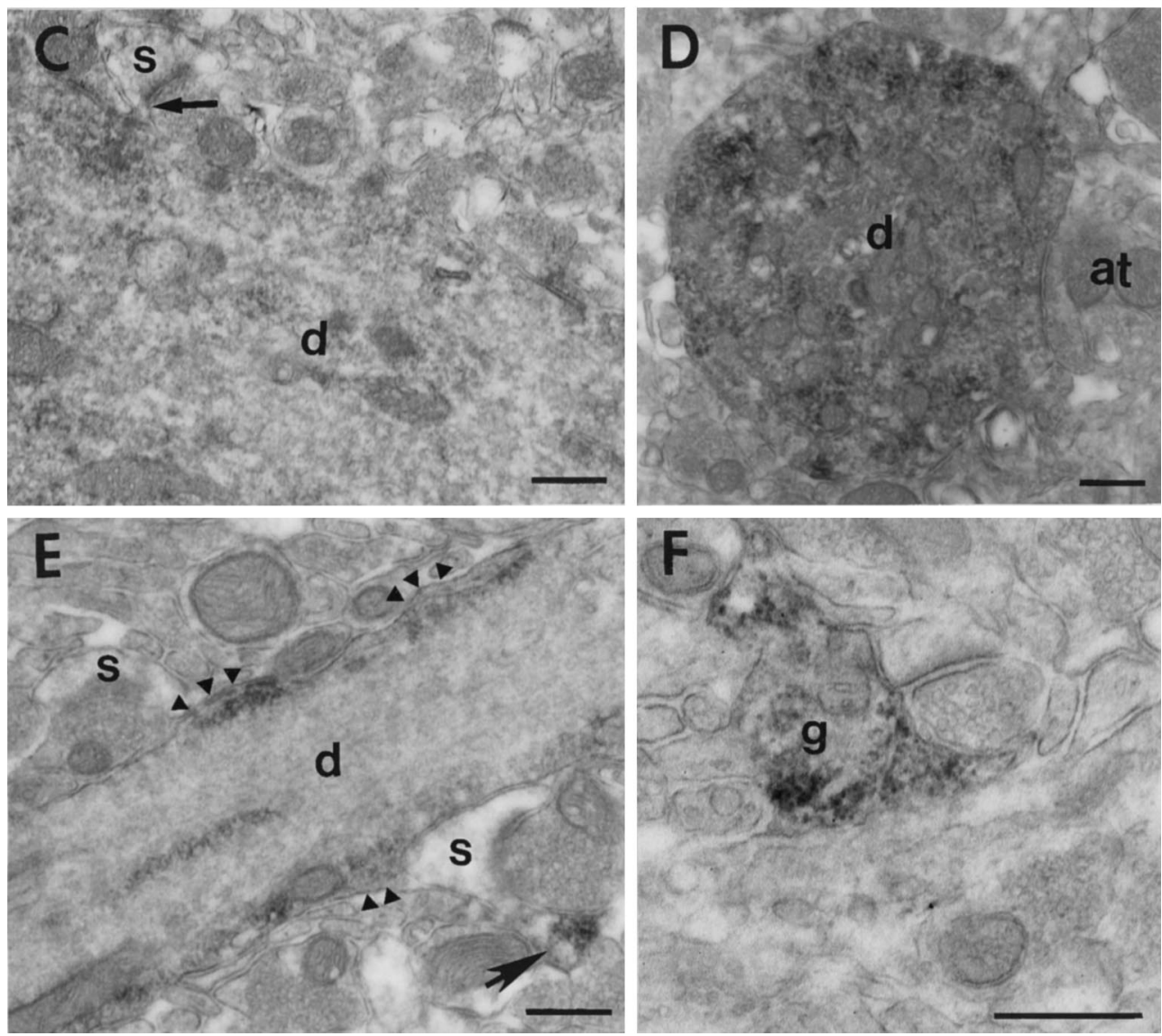

The observation of intensely labeled cisterns of endoplasmic reticulum, sometimes at the base of dendritic spines, was intriguing. No ribosomes were identified in the present study, but Steward and Reeves (1988) noted that almost half of the polyribosomes at the base of dendritic spines are juxtaposed to membrane cisterns reminiscent of RER. The possibility of RER in dendrites is interesting, because it suggests that some post-translational modification of proteins is possible at sites distant from the cell body. The presence of dendritic RER may explain why the mRNA for some integral membrane proteins has been observed within dendrites. Miyashiro et al. (1994), using highly sensitive amplification methods in isolated dendrites, provided evidence that mRNAs for some glutamate receptor isoforms are found within dendrites, although others have not been able to localize such transcripts in synaptosomes (Chicurel et al., 1993). In addition,
Furuichi et al. (1993) described strong labeling for the type 1 IP3 receptor, a calcium-release channel localized to the smooth endoplasmic reticulum, within the dendrites of Purkinje neurons. No evidence for the presence of Golgi apparatus has yet been provided for dendrites, although some have suggested that the spine apparatus may be involved in post-translational modification of proteins (Spacek, 1985; Gordon-Weeks, 1988; Steward and Reeves, 1988).

\section{mRNA and synaptic sites}

Previous studies on the distribution of polyribosomes within dendrites have indicated that these organelles are selectively localized to the base of dendritic spines and beneath synaptic sites (Steward and Levy, 1982; Steward and Falk, 1986). In the present study, a quantitative analysis of the association of labeling with synaptic 
sites was not possible because of the limited penetration of the reagents and the small sample of dendritic spines attached to labeled dendrites. Nevertheless, the majority of spines attached to a labeled dendrite had labeling concentrated at their base. Labeling was also observed consistently beneath slight bulges in the plasmalemma. Steward and Levy (1982) estimated that $\sim 70 \%$ of ribosomes were similarly found beneath these "mounds" in the dentate gyrus. Their analysis of serial sections confirmed that many of these mounds marked bases of spines out of the plane of section. Because spine numbers can change rapidly even in the adult animal (Woolley et al., 1990), some of the labeled mounds could represent sites of developing spines.

Focal labeling was not consistently observed near postsynaptic specializations on the dendritic shaft. This observation is consistent with the findings of Steward and Falk, who reported that only $6 \%$ of shaft synapses had underlying polyribosomes in 20- to 28-d-old rats. In fact, a substantial amount of labeling was found within the interior of the dendritic shaft or near regions of the plasma membrane not associated with any particular specialization. Some portion of this labeling no doubt represents mRNAs that are being transported to various regions within the dendrite. Our results suggest, however, that a substantial portion of mRNA may not be specifically associated with synaptic sites.

An interesting finding was the presence of labeling for poly(A) mRNA within the dendritic spines themselves. Labeled spines were observed within the neuropil and also in continuity with the dendritic shaft, although not all spines labeled at their base were labeled. The presence of nonspecific labeling in spine heads within the control conditions makes this result difficult to interpret. However, considerably fewer labeled profiles were observed in the controls than in the experimental condition, suggesting that at least some dendritic spines have mRNA within the head and shaft. Three-dimensional analyses of dendritic spines in various brain regions indicated that polyribosomes are also present within a sizable portion of spines (Spacek, 1985; Steward and Reeves, 1988; Chicurel and Harris, 1992; Harris and Spacek, 1995). In addition, Chicurel et al. (1993) suggested that some mRNAs may be specifically localized within spines, based on an analysis of synaptosomal preparations.

\section{Conclusions}

The results of this study support the presence of protein synthetic machinery near postsynaptic sites in hippocampal dendrites. Whether protein synthesis occurs within dendrites in vivo and whether the subcellular localization of a relatively small number of mRNAs plays an important role in neuronal functioning are unknown. That dendritic mRNAs are subject to regulation by synaptic activity is suggested by studies showing that certain stimulation conditions increased dendritic expression of CAMKII mRNA (Thomas et al., 1994) and MAP2 mRNA (Johnston and Morris, 1994) and induced the dendritic expression of mRNA for an immediate early gene (Link et al., 1995; Lyford et al., 1995). The key question is whether such stimulation also results in synthesis of functional proteins within dendrites. Indirect evidence that it does comes from studies indicating that protein synthesis in synaptoneurosomes is stimulated by metabotropic glutamate agonists and calcium release from intracellular stores (Weiler and Greenough, 1993). A more direct demonstration was provided by Feig and Lipton (1993), who found that patterned stimulation of the Schaffer collaterals combined with carbachol application induced protein synthesis in dendritic fields of hippocampal slices. Although not conclusive, these early studies indicate that local protein synthesis at the synaptic site may be an important determinant of synaptic plasticity (Weiler et al., 1994). It will be interesting to determine whether additional factors that contribute to the control of protein synthesis, e.g., elongation factors (Ryazanov et al., 1991), are present in dendrites as well. Elongation factors such as eEf-2 are sensitive to changes in calcium and phosphorylation (Nilsson and Nygard, 1995) and thus may represent one mechanism by which activity at the synapse could regulate local protein synthesis.

\section{REFERENCES}

Ainger K, Avossa D, Morgan F, Hill SJ, Barry C, Barbarese E, Carson JH (1993) Transport and localization of exogenous myelin basic protein mRNA microinjected into oligodendrocytes. J Cell Biol 123:431-441.

Bassell GJ, Singer RH, Kosik KS (1994) Association of poly(A) mRNA with microtubules in cultured neurons. Neuron 12:571-582.

Burgin KE, Waxham MN, Rickling S, Westgate SA, Mobley WC, Kelly PT (1990) In situ hybridization histochemistry of $\mathrm{Ca}^{2+} /$ calmodulindependent protein kinase in developing rat brain. J Neurosci 10:1788-1798.

Chicurel ME, Harris KM (1992) Three-dimensional analysis of the structure and composition of CA3 branched dendritic spines and their relationship with mossy fiber boutons in the rat hippocampus. J Comp Neurol 325:169-182.

Chicurel ME, Terrian DM, Potter H (1993) mRNA at the synapse: analysis of synaptosomal preparation enriched in hippocampal dendritic spines. J Neurosci 13:4054-4063.

Davis L, Banker GA, Steward O (1987) Selective dendritic transport of RNA in hippocampal neurons in culture. Nature 330:477-479.

Deerinck TJ, Martone ME, Lev-Ram V, Green DP, Tsien RY, Spector DL, Huang S, Ellisman MH (1994) Fluorescence photooxidation with eosin: a method for high resolution immunolocalization and in situ hybridization detection for light and electron microscopy. J Cell Biol 126:901-910.

Elisha Z, Havin I, Ringel I, Yisraeli JK (1995) Vg1 RNA binding protein mediates the association of Vg1 RNA with microtubules in Xenopus oocytes. EMBO J 14:5109-5114.

Feig S, Lipton P (1993) Pairing the cholinergic agonist carbachol with patterned Schaffer collateral stimulation initiates protein synthesis in hippocampal pyramidal cell dendrites via a muscarinic, NMDAdependent mechanism. J Neurosci 13:1010-1021.

Furuichi T, Simon-Chazottes D, Fujino I, Yamada N, Hasegawa M, Miyawaki A, Yoshikawa S, Guenet J-L, Mikoshiba K (1993) Widespread expression of inositol-1, 4, 5-trisphosphate receptor type 1 gene (InsP3R1) in the mouse central nervous system. Receptors Channels 1:11-24.

Garner CC, Tucker RP, Matus A (1988) Selective localization of messenger RNA for cytoskeletal protein MAP2 in dendrites. Nature 336:674-677.

Gordon-Weeks PR (1988) RNA transport in dendrites. Trends Neurosci 11:342-343.

Harris KM, Spacek J (1995) Three-dimensional organization of SER and other organelles in dendritic spines of rat hippocampus (CA1). Soc Neurosci Abstr 21:594.

Huang S, Deerinck TJ, Ellisman MH, Spector DL (1994) In vivo analysis of the stability and transport of nuclear poly(A)+ RNA. J Cell Biol 126:877-899.

Johnston HM, Morris BJ (1994) Selective regulation of dendritic MAP2 mRNA levels in hippocampal granule cells by nitric oxide. Neurosci Lett 177:5-10.

Kleiman R, Banker G, Steward O (1994) Development of subcellular mRNA compartmentation in hippocampal neurons in culture. J Neurosci 14:1130-1140.

Landry CF, Watson JB, Kashima T, Campagnoni AT (1994) Cellular influences on RNA sorting in neurons and glia: an in situ hybridization histochemical study. Mol Brain Res 27:1-11.

Link W, Konietzko U, Kauselmann G, Krug M, Schwanke B, Frey U, Kuhl D (1995) Somatodendritic expression of an immediate early gene is regulated by synaptic activity. Proc Natl Acad Sci USA 92:5734-5738.

Litman P, Barg J, Ginzburg I (1994) Microtubules are involved in the localization of tau mRNA in primary neuronal cell cultures. Neuron 13:1463-1474. 
Lyford GL, Yamagata K, Kaufmann WE, Barnes CA, Sanders LK, Copeland NG, Gilbert DJ, Jenkins NA, Lanahan AA, Worley PF (1995) Arc, a growth factor and activity-regulated gene, encodes a novel cytoskeleton-associated protein that is enriched in dendrites. Neuron $14: 433-445$.

MacDonald PM, Struhl G (1988) Cis-acting sequences responsible for anterior localization of bicoid mRNA in Drosophila embryos. Nature 336:595-598.

Martone ME, Pollock JA, Zhang Y, Ellisman MH (1993) Ultrastructural distribution of CAM kinase II isoform mRNA in rat hippocampus: electron microscopic in situ hybridization using thick cryosections. Soc Neurosci Abstr 19:1113.

Martone ME, Zhang Y, Ellisman MH (1995) mRNA is localized near post-synaptic sites in hippocampal dendrites. Soc Neurosci Abstr 21:50.

McQuaid S, Allan GM (1992) Detection protocols for biotinylated probes: optimization using multistep techniques. J Histochem Cytochem 40:569-574.

Miyashiro K, Dichter M, Eberwine J (1994) On the nature and differential distribution of mRNAs in hippocampal neurites: implications for neuronal functioning. Proc Natl Acad Sci USA 91:10800-10804.

Moriya M, Tanaka S (1994) Prominent expression of protein kinase C $(\gamma)$ mRNA in the dendrite-rich neuropil of mice cerebellum at the critical period for synaptogenesis. NeuroReport 5:929-932.

Mowry KL, Melton DA (1992) Vegetal messenger RNA localization directed by a 340-nt RNA sequence element in Xenopus oocytes. Science 255:991-994.

Nilsson A, Nygard O (1995) Phosphorylation of eukaryotic elongation factor 2 in differentiating and proliferating HL-60 cells. Biochim Biophys Acta 1268:263-268.

Peters A, Palay SL, Webster HDeF (1991) The fine structure of the nervous system: neurons and their supporting cells, 3rd Ed. New York: Oxford UP.

Phillips LL, Nostrandt SJ, Chikaraishi DM, Steward O (1987) Increases in ribosomal RNA within the denervated neuropil of the dentate gyrus during reinnervation: evaluation by in situ hybridization using DNA probes complementary to ribosomal RNA. Brain Res 388:251-261.

Pokrywka NJ, Stephenson EC (1991) Microtubules mediate the localization of bicoid RNA during Drosophila oogenesis. Development 113:55-66.

Pollock JA, Ellisman MH, Benzer S (1990) Subcellular localization of transcripts in Drosophila photoreceptor neurons: chaoptic mutants have an aberrant distribution. Genes Dev 4:806-821.

Pollock JA, Martone M, Deerinck T, Ellisman MH (1991) mRNA localization by electron microscopic in situ hybridization. In: Proceedings of the 49th annual meeting of the Electron Microscopy Society of America (Bailey GW, ed), pp 430-431.

Rao A, Steward O (1991) Evidence that protein constituents of postsynaptic membrane specializations are locally synthesized: analysis of proteins synthesized within synaptosomes. J Neurosci 11:2881-2895.
Rao A, Steward O (1993) Evaluation of RNAs present in synaptodendrosomes: dendritic glial and neuronal cell body contribution. J Neurochem 61:835-844.

Ryazanov AG, Rudkin BB, Spirin AS (1991) Regulation of protein synthesis at the elongation stage. New insights into the control of gene expression in eukaryotes. FEBS Lett 285:170-175.

Spacek J (1985) Three-dimensional analysis of dendritic spines. II. Spine apparatus and other cytoplasmic components. Anat Embryol 171:235-243.

Spector DL (1993) Macromolecular domains within the cell nucleus. Annu Rev Cell Biol 9:265-315.

Steward O (1995) Targeting of mRNAs to subsynaptic microdomains in dendrites. Curr Opin Neurobiol 5:55-61.

Steward O, Banker GA (1992) Getting the message from the gene to the synapses: sorting and intracellular transport of RNA in neurons. Trends Neurosci 15:180-186.

Steward O, Falk PM (1986) Protein-synthetic machinery at postsynaptic sites during synaptogenesis: a quantitative study of the association between polyribosomes and developing synapses. J Neurosci 6:412-423.

Steward O, Fass B (1983) Polyribosomes associated with dendritic spines in the denervated dentate gyrus: evidence for local regulation of protein synthesis during reinnervation. Prog Brain Res 58:131-136.

Steward O, Levy WB (1982) Preferential localization of polyribosomes under the base of dendritic spines in granule cells of the dentate gyrus. J Neurosci 2:284-291.

Steward O, Reeves TM (1988) Protein synthetic machinery beneath postsynaptic sites on CNS neurons: association between polyribosomes and other organelles at the synaptic site. J Neurosci 8:176-184.

Thomas KL, Laroche S, Errington ML, Bliss TVP, Hunt SP (1994) Spatial and temporal changes in signal transduction pathways during LTP. Neuron 13:737-745.

Torre ER, Steward O (1992) Demonstration of local protein synthesis within dendrites using a new cell culture system that permits the isolation of living axons and dendrites from their cell bodies. J Neurosci 12:762-772.

Weiler IJ, Greenough WT (1993) Metabotropic glutamate receptors trigger postsynaptic protein synthesis. Proc Natl Acad Sci USA 90:7168-7171.

Weiler IJ, Wang X, Greenough WT (1994) Synapse-activated protein synthesis as a possible mechanism of plastic neural change. Prog Brain Res 100:189-194.

Wenderoth MP, Eisenberg BR (1991) Ultrastructural distribution of myosin heavy chain mRNA in cardiac tissue: a comparison of frozen and LR white embedment. J Histochem Cytochem 39:1025-1033.

Wilhelm JE, Vale RD (1993) RNA on the move: the mRNA localization pathway. J Cell Biol 123:269-274.

Woolley CS, Gould E, Frankfurt M, McEwen BS (1990) Naturally occurring fluctuation in dendritic spine density on adult hippocampal pyramidal neurons. J Neurosci 10:4035-4039. 